\title{
Qualifications Frameworks in the Transition to Knowledge Community
}

\author{
Osman Yazicioglu ${ }^{1, *} \&$ Oguz Borat ${ }^{1}$ \\ ${ }^{1}$ Dept. of Industrial Engineering, Istanbul Commerce University, Kucukyali, 34840 Istanbul, \\ Turkey \\ *Correspondence: Dept. of Industrial Engineering, Istanbul Commerce University, Kucukyali, \\ 34840 Istanbul, Turkey. Tel: 90-539-786-0950. E-mail: oyazicioglu@ticaret.edu.tr
}

Received: November 16, 2019 Accepted: February 4, 2020 Published: February 14, 2020

doi:10.5296/ije.v12i1.15843ＵRL: https://doi.org/10.5296/ije.v12i1.15843

\begin{abstract}
In the transition to the knowledge community, the disciplines of knowledge management have necessitated the revision of education and employment issues. As a result, more than 140 countries around world have had to set their national priority to review their own education and employment policies considering the individual developments, community expectations and international practices associated with the "lifelong learning". The overall goal of Turkish Qualifications Framework (TQF) is to provide an integrated structure which describes and classifies all qualifications available in Turkey, allowing for links such as transfer or progression among qualifications to be determined. Thus, transparency will be improved in education and training systems, which will enable national and international comparability, recognition and validation. TQF will ensure to link all qualifications achieved either at classroom of a school, university, training center, or in a laboratory, workshop and workplace of a research center or company through formal, non-formal or informal learning. TQF structure comprises of levels described by level descriptors and supported by qualification types. Qualification types are described through qualification type specifications.
\end{abstract}

Keywords: qualifications, lifelong learning, recognition and validation of prior learning. 
1. European Qualifications Framework for Lifelong Learning - A Bridge between National Qualifications Systems

In the transition to knowledge community, knowledge management disciplines cover many issues and make it necessary to work in accordance with new technologies. Some of the diverse disciplines that have contributed to knowledge management are as follows, (Dalkir, 2011): Database technologies, collaborative technologies, organizational sciences, electronic support systems, document and information management, decision support systems, library and information sciences, web technologies, artificial intelligence, technical writing, cognitive science, help desk systems.

Qualification, according to The European Qualifications Framework (EQF) for Lifelong Learning definition (EQF, 2008); is the official printout of an assessment and verification process, which is obtained by a competent authority when it is determined that an individual has acquired learning gains according to certain standards.

Within the scope of Lifelong Learning (LLL), EQF is a common benchmark or translation tool to ensure that competencies (degrees, diplomas and certificates) between different countries and systems in Europe are more comprehensible and clearer and that countries' qualifications systems are linked (EQF, 2008; EC, 2008).

The EQF has been the catalyst for development of comprehensive national qualification frameworks based on learning outcomes. All countries committed to the EQF consider such national frameworks necessary to make their qualifications comparable across sectors and countries. In addition it is reasonable to expect commitment towards the reallocation of local priorities (Heyneman, 2016). Sector clusters with ministries and public institutions as well as NGOs responsible for the coordination and implementation of education are gaining importance (Knutsson and Lindberg, 2019).

In the decision of the European Commission numbered 2008/C111/01, which is an advisory about the EQF, it was requested that the national qualifications should be associated with the EQF levels up to 2010 by establishing the National Qualifications Framework (NQF) of each country, and as of 2012, a reference to the EQF levels was requested for all the qualification documents of the countries (Broek et al., 2012).

The EQF is not about establishing European standards or a common European education and training system. It is an approach that aims to give importance to transparency, mutual trust, mobility and involvement of stakeholders, enabling the translation of levels and qualifications between existing systems. The EQF has been a source of inspiration for the development of national and regional qualifications frameworks throughout the world. An increasing number of countries and regions are seeking closer links between their qualifications framework and the EQF.

Comparability is supported through the use of mutual trust, quality assurance and learning outcomes in EQF. The EQF does not provide automatic recognition throughout Europe. It is a tool for the development of NQF countries and for the reference of qualification systems among countries. It supports formal, non-formal and informal learning in the context of LLL; 
encourages the validation of common and informal learning. Therefore, the regulation of qualifications up to 2018 with the new perspective has been put on the agenda of EU countries.

\section{Eight Reference Levels Defined in Terms of Learning Outcomes}

The core of the EQF is its eight reference levels defined in terms of learning outcomes, i.e. knowledge, skills, and autonomy and responsibility competences. Learning outcomes express what individuals know, understand and are able to do at the end of a learning process. Countries develop their national qualifications frameworks (NQFs) to implement the EQF.

Level descriptors are the definitions of knowledge, skills and competencies that should be at the levels covered by the NQF. European Commissioner for Education and Culture asked the opinion of the Ministry of Education (MoNE) about the use of eight reference levels, descriptors and program learning outcomes in Turkey.

A survey collecting the views of institutions was conducted under the coordination of the MoNE, and as a result the use of eight reference levels, descriptors and program learning outcomes have been accepted. Finally, in 2005, the MoNE officially reported the decision of Turkey to the European Commissioner for Education and Culture.

In this context education, assessment and certification institutions related with MoNE, Council of Higher Education (CoHE) and Vocational Qualifications Authority (VQA) have begun to use the eight-level reference system in their education and qualification certificates.

In addition to traditional formal education, individuals try to develop themselves by means of non-formal and informal learning, as well as distance learning through the use of information and communication technology (ICT) tools, and even through workplace-based learning support.

In the EU countries, the areas related to the education, development and employment of individuals are called European Space and European Space is citizen-oriented.

The individual can have European Passport identity in the European Space (Euro-pass: curriculum vitae, language portfolio, diploma supplements, certificate supplements, mobility certificate), learn about learning environments (Ploteus Portal) and plan his / her career in LLL (formal, non-formal and informal learning).

The European Space covers a very large area: European Credit Transfer and Accumulation System (ECTS), European Credit Transfer and Accumulation System for Vocational Education and Training (ECVET), self-education, eight reference level to try to rise, formal and non-formal education institutions or measurement, evaluation and certification centers (Vocational Testing / Voc-Test Centers) to use the right of examination, (in the form of diplomas, degrees or certificates) to obtain a certificate of qualification, employment in the labor market.

Learning outcomes are the knowledge, skills and competences of the individual after the 
completion of any learning process. Learning outcomes are the expressions and behaviors that a learner should know, understand and do when a learning process is completed. The learning outcomes achieved by the learner are called learning achievement. The systems forming the European Space and the relations between them are given in Figure 1.

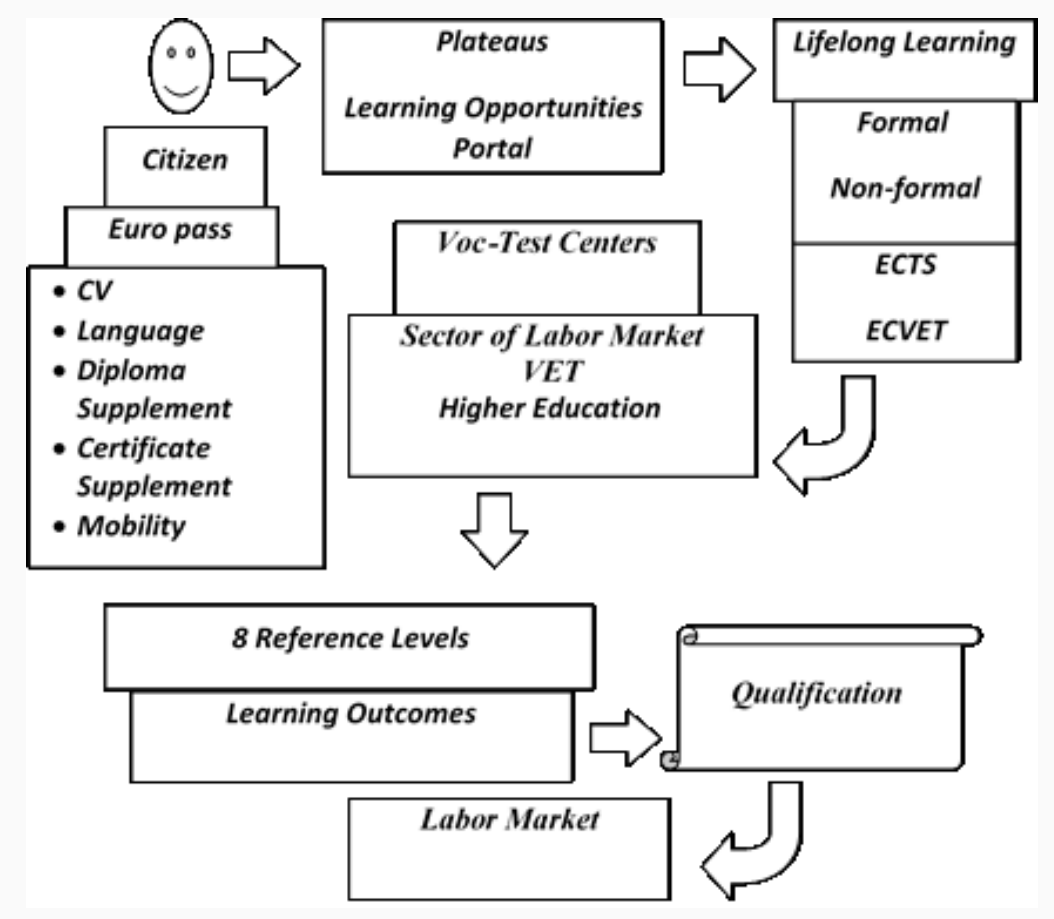

Figure 1. The European Space Systems and Their Relations (Borat, 2009).

\section{Lifelong Learning Strategies and Action Plans}

Thanks to technological advances, in addition to face to face learning, distance learning started to be used. The aim of the curriculum is to develop students face to face and distance learning methods. The student is encouraged to learn with a hybrid (blended) structure.

In this framework, simultaneous (synchronous) and asynchronous (asynchronous) distance learning programs in the MoNE and in higher education institutions and video studies related to them continue.

Graduation rates from secondary education and higher education are very low. This means a large amount of waste of resources. Turkey's spending for education and training system, which constitutes a significant part of the budget with the tax people, with donations made to foundations and is met by direct out of pocket spending. In the meantime, one of the important goals is to increase the rate of graduation.

Studies on LLL in Turkey with wide participation of public and private institutions and organizations in the Ministry of coordination was initiated in 2007 and "Lifelong Learning Strategy Document and Action Plan" was approved by the name of the Supreme Planning Council was enacted in 2009, (MoNE-BoE, 2010). According to this document, legal regulations, procedures and coordination regarding determination, identification and 
presentation of qualifications in education and training system were carried out by responsible institutions / organizations.

Turkish Lifelong Learning Strategy Document and Action Plan 2014-2018 has been prepared and implemented, (MoNE, 2014). For the preparation of the Turkish Lifelong Learning Strategy Document 2019-2023 various workshops and studies have been completed. Particularly, guidance and counseling services need to be improved and the system of recognition and validation of prior learning should be completed at different levels of qualifications for various industry and service sectors.

There is a strong consensus on the benefits of making more visible those skills and competences that people have gained through life and work experience. Individuals should be able to demonstrate what they have learned in all walks of life, so that this is valued and used in their career and for further education and training prospects. Validation of non-formal and informal learning can make a major contribution to the Turkey's objectives of achieving smart, sustainable and inclusive growth, as set by the Turkish 2023 strategy, (Borat, 2009a; Borat, 2009b).

It can make a significant difference in better matching skills and labour demand, promoting transferability of skills between companies and sectors and supporting mobility across the labour market. It can also contribute to fighting social exclusion by providing a way for early school leavers, the unemployed and others at risk, particularly low-skilled adults, to improve their employability.

The European inventory on validation of non-formal and informal learning is a fundamental support to implementing the 2012 Council recommendation on the validation of non-formal and informal learning, (EU,2012; EU, 2017). The recommendation was asking Member States to establish validation arrangements by 2018 , allowing individuals to identify, document, assess and certify their skills to obtain a qualification (or parts of it).

The inventory is closely linked to the European guidelines on validation which provide policy and practical advice to Member States and stakeholders on implementing validation. The inventory provides a unique record of how validation is being used at national, regional and local levels in Europe.

MoNE, CoHE and VQA are in charge of qualification systems. MoNE schools and higher education institutions are the institutions that give main qualifications such as diplomas and degrees. Voc-Test Centers which are NGO based enterprises and authorized by VQA give qualifications certificates. In Turkey, there are other certification bodies; detailed studies on these organizations will be clarified in the Turkey Qualifications Framework (TQF) implementation process (TQF, 2015).

In the process of change and growth, the areas open to improvement in the education and training system are:

1) Transparency and recognition of individuals' access to qualifications and mobility,

2) Learning-based qualifications and credit system, 
3) Collaboration with stakeholders.

4) Teacher and executive qualifications,

5) Participation of individuals in LLL,

6) Recognition and validation of prior learning,

7) Quality assurance,

8) Differences based on gender and geographical region,

9) Education levels of individuals of working age.

The EU's amended Lisbon 2010 Training Goals are presented in the Europe 2020 document (EC, 2010; EU Council, 2011). Targets to be reached by 2020 should be used to track developments:

1) At least $95 \%$ of children between the age of 4 and the start of primary education should have begun early childhood education,

2) The shortage of the 15 age group in the fields of Reading, Mathematics and Science should be less than $15 \%$,

3) Less than $10 \%$ drop-out rates,

4) At least $40 \%$ of the higher education rate in the 30-34 age group,

5) At least $15 \%$ of $25-64$ age groups are participating in Lifelong Learning activities.

In addition, progress should be made on sixteen key indicators to achieve the Lisbon objectives:

1) Participation in pre-school education.

2) Special education,

3) School dropout rates.

4) Literacy and number literacy.

5) Language skills.

6) ICT skills.

7) Citizenship.

8) Learning to learn.

9) Secondary graduation rate of young people.

10) Professional development of teachers and trainers.

11) Higher education graduates.

12) Education of tertiary students in different countries. 
13) Adults' participation in lifelong learning.

14) Adult Competences.

15) Education gains of the population.

16) Investment in education and training.

\section{The Importance of Informal Learning}

There are various papers on parental expectations and aspirations, and their engagement with their children's education and plans for the future. The data reported derives from wider studies on access to higher education amongst young people living in disadvantaged communities in urban and rural areas. Internationally, there is now a significant body of literature on parents' orientations to their children's education and the role which they play in supporting formal, non-formal and informal learning. It is easy to see why parents, particularly those from disadvantaged communities, might feel anxious in the current economic climate. Over the last ten years a number of European countries have seen record levels of youth unemployment and cuts in social welfare benefits for young people. According to data from the Economic and Social Research Institute, the importance of having a Leaving Certificate, or higher level of education, in reducing the risk of a young person becoming unemployed has increased since the economic crisis. This emphasizes the importance of recognition of knowledge, skills and competences gained through non-formal and informal learning, (Scanola et al., 2019).

Even in formal learning, informal negotiation and discussions, such as the practice of informal learning, are encouraged. This is an important aspect of educational classes and instructional experience. There is a considerable amount of informal discussion and debate in social studies and humanities courses. Classes usually involve Socratic exchange between the instructor and the students who choose to deal with questions or ideas in the classroom; and informal discussions between students are also encouraged by some instructors (OReilly, 2013). In other words, the individual participates better in informal environment, thinks about the subject and discovers some issues himself (OReilly, 2013).

How much of the time human life is devoted to learning is related to formal education, how much to non-formal education and how much to learn? When this type of examination is done, the result highlights informal learning (Borat 2009a, Borat 2009b, Bukel 2011).

$11.6 \%$ of the total learning time of a person between zero and seventy years of age in infancy, preschool, primary, secondary education, higher education, work and home life, was for formal education, $4.6 \%$ for non-formal education and $83.7 \%$ is reserved for informal learning (Table 1 to 4). 
Table 1. Sleep, Eat, Rest, Play, etc. Time Allocated to Needs [h=hours] (Borat, 2010)

\begin{tabular}{|c|c|c|c|c|c|c|c|}
\hline \multirow[b]{2}{*}{ Period } & \multirow[b]{2}{*}{$\begin{array}{l}\text { Age } \\
\text { range }\end{array}$} & \multirow[b]{2}{*}{$\begin{array}{l}\text { Total } \\
\text { Year }\end{array}$} & \multicolumn{2}{|c|}{ Daily 24 (h) } & \multicolumn{2}{|c|}{ Total Life Cycle } & \multirow[b]{2}{*}{$\begin{array}{l}\text { Life Time } \\
\text { (h) }\end{array}$} \\
\hline & & & Sleep & $\begin{array}{c}\text { Dining, } \\
\text { Relaxing } \\
\text { etc. }\end{array}$ & Sleep & $\begin{array}{c}\text { Food, } \\
\text { Rest etc. }\end{array}$ & \\
\hline Infancy & $0-3$ & 3 & 14 & 6 & 15330 & 6570 & 26280 \\
\hline Pre-school & $3-6$ & 3 & 12 & 7 & 13140 & 7665 & 26280 \\
\hline Primary education & $6-14$ & 8 & 10 & 7 & 29200 & 20440 & 70080 \\
\hline Secondary education & $14-18$ & 4 & 8 & 7 & 11680 & 10220 & 35040 \\
\hline Higher education & $18-22$ & 4 & 8 & 7 & 11680 & 10220 & 35040 \\
\hline Work and Home Life & $22-70$ & 48 & 7 & 7 & 122640 & 122640 & 420480 \\
\hline Total & & 70 & & & 203670 & 177755 & 613200 \\
\hline
\end{tabular}

Table 2. Periods Devoted to Formal Education in Various Periods of Life [h=hours] (Borat, 2010)

\begin{tabular}{lccccccc}
\hline \multirow{2}{*}{ Period } & \multirow{2}{*}{$\begin{array}{c}\text { Age } \\
\text { range }\end{array}$} & Total & \multicolumn{5}{c}{ Formal education } \\
\cline { 5 - 8 } & & Year & & Weekly (h) & Week/Year & Year (h) & Total (h) \\
\hline Infancy & $0-3$ & 3 & 0 & 0 & 0 & 0 \\
Pre-school & $3-6$ & 3 & 30 & 36 & 1080 & 3240 \\
Primary education & $6-14$ & 8 & 40 & 36 & 1440 & 11520 \\
Secondary education & $14-18$ & 4 & 40 & 36 & 1440 & 5760 \\
Higher education & $18-22$ & 4 & 45 & 36 & 1620 & 6480 \\
Work and Home Life & $22-70$ & 48 & 0 & 0 & 0 & 0 \\
Total & & 70 & & & & 27000 \\
\hline
\end{tabular}

Table 3. Periods of Non-formal Education in Various Periods of Life (Borat, 2010)

\begin{tabular}{|c|c|c|c|c|c|c|}
\hline \multirow{2}{*}{ Period } & \multirow{2}{*}{$\begin{array}{l}\text { Age } \\
\text { range }\end{array}$} & \multirow{2}{*}{$\begin{array}{l}\text { Total } \\
\text { Year }\end{array}$} & \multicolumn{4}{|c|}{ Non-Formal Education (h) } \\
\hline & & & Weekly (h) & Week/Year & Year $(\mathrm{h})$ & Total (h) \\
\hline Infancy & $0-3$ & 3 & 0 & 0 & 0 & 0 \\
\hline Pre-school & $3-6$ & 3 & 0 & 0 & 0 & 0 \\
\hline Primary education & $6-14$ & 8 & 0 & 0 & 0 & 0 \\
\hline Secondary education & $14-18$ & 4 & 4 & 20 & 80 & 320 \\
\hline Higher education & $18-22$ & 4 & 10 & 20 & 200 & 800 \\
\hline Work and Home Life & $22-70$ & 48 & 10 & 20 & 200 & 9600 \\
\hline Total & & 70 & & & & 10720 \\
\hline
\end{tabular}




\section{Ml Macrothink}

Table 4. Periods and Percentages for Formal and Non-formal Education and Informal Learning in Various Periods of Life (Borat, 2010)

\begin{tabular}{|c|c|c|c|c|c|c|c|c|}
\hline \multirow[b]{2}{*}{ Period } & \multirow{2}{*}{$\begin{array}{l}\text { Age } \\
\text { range }\end{array}$} & \multirow{2}{*}{$\begin{array}{l}\text { Total } \\
\text { Year }\end{array}$} & \multicolumn{3}{|c|}{ Total Learning (h) } & \multicolumn{3}{|c|}{ Learning \% } \\
\hline & & & Formal & $\begin{array}{c}\text { Non-Fo } \\
\text { rmal }\end{array}$ & Informal & Formal & $\begin{array}{l}\text { Non-F } \\
\text { ormal }\end{array}$ & Informal \\
\hline Infancy & $0-3$ & 3 & 0 & 0 & 4380 & 0.0 & 0.0 & 100.0 \\
\hline Pre-school & $3-6$ & 3 & 3240 & 0 & 2235 & 59.2 & 0.0 & 40.8 \\
\hline Primary education & $6-14$ & 8 & 11520 & 0 & 8920 & 56.4 & 0.0 & 43.6 \\
\hline Secondary education & $14-18$ & 4 & 5760 & 320 & 7060 & 43.8 & 2.4 & 53.7 \\
\hline Higher education & $18-22$ & 4 & 6480 & 800 & 5860 & 49.3 & 6.1 & 44.6 \\
\hline Work and Home Life & $22-70$ & 48 & 0 & 9600 & 165600 & 0.0 & 5.5 & 94.5 \\
\hline Total & & 70 & 27000 & 10720 & 194055 & 11.6 & 4.6 & 83.7 \\
\hline
\end{tabular}

\section{National Qualification Systems and National Qualifications Framework within the Scope of Lifelong Learning}

The National Qualification System (NQS) is the structuring of all aspects of activities in the country relating to the recognition of learning and other mechanisms, linking education and training to the labor market and civil society. As can be seen, the orientation of the education sector towards the society and the business world comes to the fore in defining the National Occupational Standards (NOS). The following institutional arrangements and processes have to be developed and implemented.

1) Defining and developing the National Occupational Standards (NOS) and qualifications

2) Establishing the National Qualification Framework (NQF).

3) Establishment of Quality Assurance (QA) system (processes and procedures, quality cycle, internal and external evaluation).

4) Establishment of Measurement, Evaluation and Certification Centers (Voc-Test Center).

5) Qualification (degrees, diplomas and certificates).

6) Establishing the necessary infrastructure for international benchmarking and equivalence.

7) Supporting LLL; facilitating horizontal, vertical and cross transitions to learning environments and reference levels, building a flexible structure.

8) Facilitating employer access to qualified manpower.

9) Increasing employment.

10) Providing individuals with assurance regarding the work area. 
11) Increasing efficiency and competitiveness.

12) Establishing a fair, transparent and reliable system.

The National Qualification Framework (NQF) is a set of principles and rules that are used to define qualifications for a country classify and compare them according to established criteria. It facilitates the qualifications to be more transparent and identifiable within the framework of quality standards and the horizontal and vertical mobility of learners among the qualifications.

Instead of $\mathrm{N}$ in the abbreviation $\mathrm{NQF}$, usually the first letter of the country name is written: TQF is written instead of NQF.

- The quality of education and training system will increase,

- The relationship between employment and education will be strengthened,

- Education and training needs of all individuals in the society will be supported by LLL opportunities,

- The skills and competencies required by the labor market will be improved.

More than 150 countries around the world are working on NQF. The main elements and tools that countries take into account within the scope of NQF are very similar.

Main elements of the countries taken into consideration in NQF

- Key Competences (EC, 2006, TQF, 2016)

- Eight Reference Level and Descriptors (TQF, 2016)

- Quality assurance (ENQA, 2009; EQAVET, 2009; TQF, 2016)

- The tools that the countries will use for citizens of NQF

- Learning Opportunities Portal

- Counseling and Guidance

- Credit Transfer and Accumulation System (TQF, 2016)

- Recognition, Validation and Accreditation of Prior Learning (Borat, 2012; TQF, 2016)

\section{National Occupational Standards}

National Occupational Standards (NOS) prepared by relevant sectors across the country can be used in a variety of ways:

- Determining the content of professional and professional qualifications

- Determining the content of training programs

- Establishing the basis for company / organization competence frameworks 


\section{Macrothink}

- Establishing the basis for various professional qualifications

- Providing business license in industry

- Improving skill levels and operational efficiency

- To be the basis for all types of human resources management and development activities, including:

- Workforce planning

- Performance evaluation and development systems

- Job descriptions

- Preparation of vacant positions and skill needs maps

- Workplace coaching

- Modeling and continuous professional development by modeling others

The NOS is used to prepare learning outcomes that are more competently based, covering the knowledge, skills and competencies of the programs in the formal and non-formal education system.

The training program under an educational standard is designed to cover more than one occupational standard. In other words, preparing a training program for each profession was a very expensive education system.

\section{Turkish Qualifications Framework for Lifelong Learning}

Turkey Qualifications Framework (TQF) has been prepared under the coordination and with the participation of the Vocational Qualifications Authority by the National Qualifications Framework Preparation Commission and technical working groups which comprise of representatives from the Ministry of National Education and Council of Higher Education, and social partners. TQF design provides for a single integrated structure to describe and classify all quality assured qualifications so that links among qualifications can be determined. TQF offers a reference framework for existing qualifications. TQF implementation will also allow for the development of new qualifications, recognition and validation of prior learning, and mutual recognition and comparison with international qualifications.

TQF designed to comply with the European Qualifications Framework (EQF); national qualifications framework, including primary, secondary and higher education, showing all qualifications principles acquired through vocational, general and academic education and training programs and other learning pathways (TQF, 2013; TQF, 2015; TQF, 2016). Here, national qualifications framework, an international concept; TQA is the name of this concept is specific to Turkey.

The purpose of TQF; to provide an integrated structure in which all learning environments are 


\section{Macrothink}

acquired and quality assured qualifications are defined, classified, transition relations between qualifications are determined and lifelong learning is supported.

All qualifications gained through vocational, general and academic education and training programs and other learning paths, including first, secondary and tertiary quality assured are covered by the TQF. TQF; it is designed as a participatory, open-minded, inclusive and inclusive framework. Principles of TQF:

- Classify all qualifications with quality assurance at national level through defined levels based on learning outcomes.

- To ensure transparency and recognition of qualifications.

- Facilitate access to qualification processes.

- Enabling crediting of qualifications, merging of credits and enabling transition between qualifications.

- To enable the design of new qualifications.

- To ensure that qualifications are prepared based on learning outcomes.

- To provide recognition of prior learning.

- Support lifelong learning.

- To strengthen the relationship between education and employment.

- To ensure the participation and contributions of the stakeholders and to realize effective cooperation between the responsible institutions.

- To comply with the European Qualifications Framework.

- To establish common concepts in order to ensure international comparability of qualifications.

- To ensure the recognition of qualifications developed by professional bodies and other institutions and organizations and which have quality assurance.

The benefits of TQF can be listed as follows:

A clear and consistent method for identifying, classifying and comparing qualifications; having defined, measurable and internationally comparable qualifications,

Bringing together qualifications with different objectives and qualifications under qualification types; establishing the basis for equivalence, recognition, progress and transition between different levels and types of qualifications; To provide a range of concepts, approaches and common language, especially level and level descriptors, to improve existing competences and to create new qualifications for institutions and all individuals in education and business world,

Expressing qualifications within the scope of TQF through learning outcomes; the ability to make a horizontal and vertical transfer between credit system, credit transfer and accumulation 
and qualifications; recognition of competencies acquired in common and informal learning environments; using learning outcomes as a reference in determining the level of achievement of an individual in recognition and validation of prior learning;

Establishing the basis for the preparation of quality assurance systems; establishing a single (integrated) framework covering all qualifications that are assured of quality throughout the country; development of institutional cooperation of all parties involved in the activities realized,

Official recognition and certification of the achievement of a competence expressed by learning outcomes; international recognition and transparency of qualifications given; ensuring national and international mobility of individuals; number and quality of employment improvement; thus, increased value added,

Supporting individuals to access learning opportunities and develop competences within the framework of LLL become more qualified. Recognition of prior learning of individuals, serving the acquisition of key competencies, and supporting LLL has importance.

The reference of TQF to EQF has a historical importance in terms of showing that the education, training and qualification system of Turkey has reached European norms as a result of the studies carried out in the last 15 years.

In the upcoming period, the TQF will be actively implemented and expanded by enhancing the quality of the education and training system and strengthening the relations between education and employment. Turkey Higher Education Qualifications Framework (THEQF) has been prepared by the CoHE, and this THEQF is under the TQF.

Turkish Qualifications Framework (TQF) according to the legislation and documentation (TQF 2015, TQF, 2016); it is the official document obtained by the responsible institution when the individual is recognized at the end of an evaluation and validation process that he / she has acquired learning outcomes according to certain criteria. These two definitions say the same thing. Preparing the qualifications to be included in the TQF by learning outcomes approach and TQF should be designed on this basis. Qualification is an official document attesting a fact, a degree, diploma and certificate.

Turkey's Referencing Report offers evidence of the compatibility of TQF with the EQF, which is discussed in the competent body of the European Commission in Brussels held EQF Advisory Group are in the 40th meeting in March 29, 2017.

Turkey at the meeting was represented by a delegation consisting of officials from the Ministry of Education, the CoHE and the VQA. Turkey Referencing Report evaluated by the EQF Advisory Group open, transparent and reliable operation and as a result of negotiations, it was decided that the TQF to EQF referenced, (TQF, 2017).

By April 2018, 35 countries had formally linked ('referenced') their national qualifications frameworks to the EQF: Austria, Belgium (Flanders and Wallonia), Bulgaria, Croatia, South Cyprus, the Czech Republic, Denmark, Estonia, Finland, the Former Yugoslav Republic of Macedonia, France, Germany, Greece, Hungary, Iceland, Ireland, Italy, Kosovo, Latvia, 
Lichtenstein, Lithuania, Luxembourg, Malta, Montenegro, the Netherlands, Norway, Poland, Portugal, Romania, Slovakia, Slovenia, Sweden, Switzerland, Turkey and the United Kingdom (England, Scotland and Wales). The remaining countries are expected to follow in 2019, which means that the first stage of EQF referencing is nearly finished.

\section{Vocational Qualifications Authority (VQA)}

The qualifications given to individuals are given to demonstrate their level of achievement in learning outcomes, for example levels of access to knowledge, skills and competence. The surveys indicate that the labor market sees inadequate qualifications given by educational institutions. These two types are interpreted:

1) Knowledge, skills and competences which are the learning outcomes declared by the institutions, do not correspond to the individual's achievement levels; the graduates are much in terms of knowledge and skills.

2) The knowledge and especially the skills expected by the labor market are different from the learning outcomes of educational institutions; the achievements of graduates do not work in the business world.

The labor market in the whole world looks at the fact that learning outcomes (knowledge, skills and competence) have been acquired, rather than where and how they are acquired.

Therefore, the human resources units of the enterprises had to make a serious measurement and evaluation on the individuals they would employ. The method of addressing the assessment and evaluation process through the NGOs representing the labor market has started to become widespread.

The VQA was established with the Law no. 5544 of 21 September 2006 to establish and operate the National Qualification System (NQS) in line with EU qualifications principles (VQA Law, 2006).

It is responsible for the fulfillment of the following tasks in cooperation with stakeholders representing many institutions and organizations. VQA is a public institution with a special budget, having administrative and financial autonomy.

The main duties of the VQA determined by law are as follows: Identifying National Occupational Standards (NOS) and National Qualifications; establish and operate the measurement, evaluation and certification system; to ensure the accreditation of education and training institutions; developing the NQF (KHK, 2011); to ensure quality assurance of all qualifications related to vocational and technical education; as the National Coordination Point, there are duties such as description of reference levels in the NQF, preparing the report and ensuring the participation of all relevant stakeholders in the process.

In the LLL Strategy Paper and Action Plan, VQA has been assigned to support and promote LLL, (MoNE-BoE, 2010). According to the NQF, organizations that wish to conduct examination, measurement and evaluation activities apply to the VQA and those who meet the 
requirements are authorized.

Accredited and authorized certification bodies carry out measurement, evaluation and certification activities. Those who are successful in the examinations are given the Vocational Qualification Certificate. In Turkey VQA authorizes an NGO representing the relevant sectors; the measurement, evaluation and certification activities required by the sector are carried out by this NGO, (VQA, 2006; VQA, 2008).

\section{Recognition and Validation of Prior Learning for Education and the Labor Market}

As it is mentioned, qualifications within the scope of TQF can be expressed through learning outcomes. By means of credit transfer and accumulation system, individuals can make a horizontal and vertical transfer between qualifications. It is possible to recognize prior learning of individual as a qualifications level, and also it can be assessed whether competencies acquired in common and informal learning environments are valid in labor market. In other words, learning outcomes can be used as a reference in determining the level of achievement of an individual in recognition and validation of prior learning.

Globalization, digitalization and migration are changing the way we work and learn. Increasing skills mismatches and the challenge of integrating all learners into work and education call for everyone involved to act. Validation of prior learning (VPL) as a stimulus and 'guide' for sustainable personal, organizational and societal development is more relevant than ever. Validation is the process of making visible and giving value to individuals' learning achievements, irrespective of their learning pathways. Some forums on VPL are prepared to strengthen the dialogue between policy-makers, practitioners, users of validation as well as other stakeholders in the process. The following VPL policy areas will be investigated:

1) Organizational arrangements: how can bridges be built among stakeholders from the worlds of business, volunteering, and education for VPL results to have value?

2) Financing: what forms of financing must in place to make VPL accessible to all learners?

3) Procedures and instruments: what kinds of procedures and instruments provide valid results and can cater for a large number of candidates?

4) Support structures: what support structures must be available to reach disadvantaged learners?

5) Post-validation pathways: what follow-up actions are required for validation to facilitate further learning and career paths?

6) Legal foundations: what issues need to be addressed by laws and regulations for VPL to be effective? 


\section{Higher Education Quality Council}

The quality assurance system can be defined as a system of activities and systematically developed activities to meet the quality requirements set for a product or service (HEQC, 2015; HEQC, 2017; HEQC, 2018). The system of quality assurance in higher education is the whole of the planned and systematic activities carried out by the institution with the approach of continuous improvement of management, education and research and development activities.

Accreditation is an evaluation and external quality assurance process that measures whether academic and field-specific standards are predetermined by an external evaluator in a given area.

The quality assurance system can be defined as a system of activities and systematically developed activities to meet / meet the quality requirements set for a product or service. The system of quality assurance in higher education is the whole of the planned and systematic activities carried out by the institution with the approach of continuous improvement of management, education and research and development activities.

Institutional External Evaluation is the evaluation of the performance of the institution in terms of achieving the mission, vision and targets it has created in order to produce or service the products according to predetermined criteria. The external evaluation process of the higher education involves the evaluation of the institution through an evaluation team organized by the Higher Education Quality Council by taking advantage of the internal evaluation process of the institution. This process, unlike program evaluation and accreditation, is focused on the overall assessment of the institution. In addition, while the external evaluation process is a feedback that evaluates the whole institution, accreditation is a qualification document given within the criteria used by the evaluating institution for the education of higher education institution.

Higher Education Quality Council is a public legal entity with administrative and financial autonomy and special budget founded with the aim of evaluating the quality levels of higher education institutions' education and research activities and administrative services in accordance with the national and international quality standards, and coordinating the processes of accreditation, internal and external quality assurance, and authorization of independent external evaluation organizations.

Higher Education Quality Council is made up of 13 members. The following constitutes the primary duties of the Council:

- Performing external evaluation of higher education institutions.

- Coordinating the authorization and recognition processes of accreditation agencies.

- Ensuring the internalization and dissemination of quality assurance culture in higher education institutions. 


\section{Conclusion}

National qualifications frameworks are gaining importance in countries and awareness of related sectors is increasing. It is very important for the individual and the society to determine the personal gains through qualifications and to ensure that qualifications are accepted and validated among countries. In this regard, countries conduct various studies on formal, non-formal and informal learning systems and try to improve their learning outcomes, measurement and evaluation. With all these efforts, international mobility, employment, validation and validation of qualifications gain importance, which has a positive impact on international relations. National qualifications frameworks are gaining importance in countries and awareness of related sectors is increasing. It is very important for the individual and the society to determine the personal gains through qualifications and to ensure that qualifications are accepted and validated among countries. In this regard, countries conduct various studies on formal, non-formal and informal learning systems and try to improve their learning outcomes, measurement and evaluation. With all these efforts, international mobility, employment, validation and validation of qualifications gain importance, which has a positive impact on international relations.

\section{Acknowledgement}

The research is financed by Istanbul Commerce University Publication, Research, and Project Coordination Board (YAPKO).

\section{References}

Borat, O. (2009a). Institutional-Sectoral Interactions for the Validation of Informal Learning. The Proceedings Book: Conferences of Establishing a Collective Understanding and Raising Awareness on Informal Learning in Turkey in the Context of Lifelong Learning Through Multi-Stake Consultation Processes Project. Ministry of National Education, Board of Education, pp. 251-275, Ankara.

Borat, O. (2009b). Examining the Formal and Non-formal Education Systems to establish Informal Education Systems. The Proceedings Book: Conferences of Establishing a Collective Understanding and Raising Awareness on Informal Learning in Turkey in the Context of Lifelong Learning Through Multi-Stake Consultation Processes Project. Ministry of National Education, Board of Education, pp. 295-308, Ankara.

Borat, O. (2010). Importance of Ensuring the Validity of Informal Learning. Education Board of the Ministry of National Education. Conference on Openings for the Validation of Informal Learning within the Lifelong Learning. Antalya, 13-14 May 2010.

Borat, O. (2012). Validation of Formal, Non-formal and Informal Leaning and Turkish Qualifications Framework, Lifelong Learning Culture and Vocational Education and Training, 16-17 June 2012, Feshane, Istanbul; Proceedings: IBB-ISMEK Publications, 
pp.80-85, Istanbul.

Broek, S., Buiskool, B. J., Oploo, M., \& Visser, S. (2012). State of play of the European Qualifications Frameworks Implementation; Study (This document was requested by the European Parliament's Committee on Education and Culture). Directorate-General for Internal Policies, Policy Department B: Structural and Cohesion Policies. Culture and Education. IP/B/CULT/FWC/2010-001/Lot2/C1/SC1. PE 474.537 Brussels, European Union, March 2012.

Bukel. I. (2011). Conference on Roles of Key Stakeholder for Recognition and Validation of Informal Learning. Information Document. Board of Education, Ministry of National Education. Hatay. June 23, 2011.

Dalkir, K. (2011). Knowledge Management in Theory and Practice (2nd Ed.). Cambridge, Massachusetts, London, The MIT Press.

EC. (2006). Key Competences. Recommendation of the European Parliament and of the Council of 18 December 2006 on Key Competences for Lifelong Learning, 2006/962/EC). The European Parliament and the Council of the European Union. Official Journal of the European Union, No. L 394/13. 30.12.2006.

EC. (2008). The European Qualifications Framework (EQF) for Lifelong Learning. The European Commission. Luxembourg, 23 April 2008.

EC. (2010). Communication from the Commission Europe 2020, a strategy for smart, sustainable and inclusive growth, COM (2010) 2020. Brussels, 03.03.2010.

EC. (2012). Proposal for a Council Recommendation on the validation of non-formal and informal learning. European Commission, Brussels, COM (2012) 485 final, 2012/0234 (NLE). 5.9.2012

EC. (2017). European inventory on validation of non-formal and informal learning - 2016 update. Synthesis report. European Centre for the Development of Vocational Training (Cedefop), Luxembourg.

ENQA. (2009). Standards and Guidelines for Quality Assurance in the European Higher Education Area. (3rd ed). Helsinki: European Association for Quality Assurance in Higher Education.

EQAVET. (2009). Recommendation of the European Parliament and of the Council of 18 June 2009 on the establishment of a European Quality Assurance Reference Framework for Vocational Education and Training. 2009/C 155/01. Recommendation of the European Parliament and of the Council of 18 June 2009.

EQF. (2008). Recommendations European Parliament Council. Recommendation of The European Parliament and of The Council of 23 April 2008 on the establishment of the European Qualifications Framework for lifelong learning. Official Journal of the European Union (2008/C 111/01). 06.05.2008. 
HEQC. (2015). Higher Education Quality Assurance Regulation. Official Gazette Date 23 July 2015, Number: 29423.

HEQC. (2017). The Law on the Amendment of Certain Laws and Decree Laws for the Development of Industry and Supporting Production. 2547 Law Additional Article 35. Date of Law 1 July 2017, Number: 7033.

HEQC. (2018). Higher Education Quality Assurance and Higher Education Quality Council Regulation. Official Gazette Date 23.11.2018, Number: 30604.

Heyneman, S. P. (2016). International organizations and the future of education assistance. International Journal of Educational Development, 48, 9-22. https://doi.org/10.1016/j.ijedudev.2015.11.009

KHK. (2011). Decree Law on the Amendment of the Law on the Organization and Duties of the MoLSS and Certain Laws and Decree Laws. Official Gazette No: 26312, Date 2 November 2011. Ankara.

Knutsson, B., \& Lindberg, J. (2019). The post-politics of aid to education: Rwanda ten years after Hayman. International Journal of Educational Development, 65, 144-151. https://doi.org/10.1016/j.ijedudev.2018.04.003

MEB-BoE. (2010). Lifelong Learning Strategy Paper and Action Plan. The Board of Education of the Ministry of National Education, 2009. High Planning Council Decision No.2009 / 21, Date: 05.06.2010. Ankara.

MONE. (2014). Turkish Lifelong Learning Strategy Paper and Action Plan. The Ministry of National Education, Ankara.

OReilly, P. (2013). Implementing and Assessing Student Performance Skills and Learning: A Policy Role-Playing Exercise. International Journal of Education, 5(1), 103-119. https://doi:10.5296/ije.v5i1.3137

Scanlon, M., Powell, F., Leahy, P., Jenkinson, H., \& Byrne, O. (2019). 'No one in our family ever went to college': Parents' orientations towards their children's post-secondary education and future occupations. International Journal of Educational Research, 93(2019), 13-22. https://doi.org/10.1016/j.ijer.2018.09.005

TQF. (2015). Turkish Qualifications Framework and Procedures on the Implementation of the Regulation on the Principles. The Council of Ministers Decision No.2015 / 8213, Date: 09/11/2015. Official Gazette No.29537, Date: 19/11/2015.

TQF. (2016). Communiqué on the Turkish Qualifications Framework, Communiqué No: 2015/1. Vocational Qualifications Authority, Official Gazette No.29581, Date: $02 / 01 / 2016$.

TQF. (2017). Turkey's Referencing Report, the compatibility of TQF with the EQF. The competent body of the European Commission. EQF Advisory Group, the 40th meeting, in Brussels, March 29, 2017. 
VQA. (2006). The Law of the Vocational Qualifications Authority. Official Gazette No. 26312, Date: October 7, 2006.

VQA. (2008). Vocational Qualification, Examination and Certification Regulation. Vocational Qualification Authority. Official Gazette No.: 27096, 30 December 2008.

\section{Copyright Disclaimer}

Copyright for this article is retained by the author(s), with first publication rights granted to the journal.

This is an open-access article distributed under the terms and conditions of the Creative Commons Attribution license (http://creativecommons.org/licenses/by/3.0/). 